\title{
Tensions and contradictions in family court innovation with high risk parents: the place of family drug treatment courts in contemporary family justice
}

Professor Judith Harwin a, ${ }^{\text {a, }}$, Professor Karen Broadhurst ${ }^{\mathrm{b}}$, Associate Professor Stephanie Taplin ${ }^{\mathrm{c}}$ and Professor Caroline Cooper ${ }^{\mathrm{d}}$

${ }^{a}$ School of Law, Lancaster University

${ }^{\mathrm{b}}$ Department of Sociology, Lancaster University

${ }^{\mathrm{c}}$ Institute of Child Protection Studies, Australian Catholic University

${ }^{\mathrm{d}}$ Justice Consultant, Researcher

* Correspondence to Professor Judith Harwin, School of Law, Bowland North, 


\section{Tensions and contradictions in family court innovation with high risk parents: the place of family drug treatment courts in contemporary family justice}

\section{Key Words}

Family drug treatment courts; parental substance misuse; court reform; child protection; neglect and abuse

\section{Abstract}

Parental substance misuse is a leading factor in child abuse and neglect and frequently results in court-mandated permanent child removal. Family drug treatment courts, which originated in the USA and are only found in adversarial family justice systems, are a radical innovation to tackle this problem. Unlike ordinary court, they treat parents within the court arena as well as adjudicating, and in this way they seek to draw a new balance between parental needs and the child's right to timely permanency. Family drug treatment courts have spread to England, Australia and Northern Ireland and international research has found they have higher rates of parental substance misuse cessation and family reunification and lower foster care costs than ordinary courts. Yet their growth has been far from straightforward. In the USA they have not kept pace with the rise of criminal drug treatment courts and in England and Australia their numbers remain small. The central purpose of this article is to explore why the family drug treatment movement has not achieved wider impact and to consider opportunities and challenges for its future development. To address these questions we draw on evidence and experience from the USA, England and Australia. We discuss the operational challenges, tensions between children's needs for stability and parental timescales for recovery, the 
impact of wider economic and political change, and issues in data evaluation. We conclude that despite the promise of family drug treatment courts as a new paradigm to address risky parenting, effecting systemic change in the courts is extremely difficult.

\section{Introduction}

The rise of the family drug treatment court (FDTC) ${ }^{1}$ as an alternative to conventional adversarial family court ${ }^{2}$ proceedings involving child abuse and neglect matters, has been one of the most radical international developments in family justice over the last three decades. FDTCs are only found in adversarial systems and they originated in the USA. They aim to treat parental substance misuse problems as well as to adjudicate regarding questions about whether children should remain at home or return if already removed, or be removed permanently from their parents' care. These decisions are amongst the most important that courts dealing with care and protection or dependency matters can make; they are mandated to override parental consent as necessary and can sever children's legal relationship with their birth family permanently. The court's paramount consideration is the child's best interests. Removal is a common course of action in cases of parental substance misuse, whether it be into adoption, guardianship, foster or kinship care.

Family drug treatment courts (FDTCs) have now spread to England, with pilot initiatives also emerging in Australia and, most recently, in Northern Ireland (Review Group, 2016).

Underpinned by a body of theory known as therapeutic jurisprudence (Winick, 2002), FDTCs differ from ordinary proceedings operationally and in their paradigm to overcome polarisation between child and parental needs. Within the FDTCs, parents receive intensive

\footnotetext{
${ }^{1}$ Family drug treatment courts are also known as family drug courts but in England, the main term is Family Drug and Alcohol Court. Although termed "courts" they are actually dockets within the general court system that oversees child abuse and neglect cases in the local jurisdiction. For consistency we shall refer to them as family drug treatment courts (FDTCs) when referring to these types of courts in the USA and Australia and use the term Family Drug and Alcohol Court (FDAC) for their English equivalent.

${ }^{2}$ In Australia the state and territory Children's Court hear care and protection matters, not family courts.
} 
assessment and support from a multidisciplinary treatment team, meet with the judge (or in Australia, the magistrate) and treatment team on a frequent basis. The judge oversees the progress of the parents, children, and service providers in carrying out the treatment plan. Research from the USA and England has consistently demonstrated higher substance misuse cessation and family reunification rates for FDTC participants compared to cases heard in ordinary courts (Harwin, Alrouh, Ryan \& Tunnard, 2014; Harwin, Alrouh, Ryan, McQuarrie, Golding, Broadhurst, Tunnard \& Swift, 2016; Worcel, Furrer, Green, Burrus \& Finigan, 2007). In England, in 2014 the President of the Family Division called for family drug courts to be embedded nationally on the basis of their promising results and compassionate approach to justice (Munby, 2014). Yet their growth has been far from straightforward. In the USA (Cooper, 2017), these new family courts have not kept pace with the rise of criminal drug treatment courts and in England their numbers remain low. In the USA a number of FDTCs have closed and in England a small number of FDAC teams no longer provide an FDAC service. In Australia only one pilot court has been established and support for additional FDTCs has not translated into funding.

The central purpose of this article is to explore why the FDTC movement has not achieved wider impact and to consider opportunities and challenges for its future development. To address these questions we draw on evidence and experience from the USA, England and Australia, identifying synergies and differences in light of the wider socio-political and economic contexts in each society and different lengths of experience with FDTCs. We start by explaining further how FDTCs differ from ordinary courts before describing their evolution in the USA, England and Australia. We then explore key factors that have undermined greater roll-out to-date in the USA and England where, unlike Australia which began a pilot FDTC only recently, there is sufficient history to reflect on these matters. These factors include operational challenges, tensions between children's needs for stability and 
parental timescales for recovery, the impact of wider economic and political change, and issues in data evaluation. We conclude with a discussion of prospects for the future of FDTCs in these different jurisdictions in light of the synergies and differences we have identified. It is now over 20 years since FDTCs first started in the USA and this article provides a long overdue critique of their achievements and challenges within a cross national context.

\section{FDTCs- a member of the family of problem-solving courts}

The first problem-solving courts operated in the criminal jurisdiction, starting with an adult drug court that opened in Florida in 1989. Today there are many different kinds of problemsolving courts that include mental health courts as well as adult drug courts and FDTCs. Problem-solving courts are based on the premise that the law has a 'considerable impact on emotional life and psychological well-being' and they construe the law as a 'social force that can produce therapeutic or anti-therapeutic consequences' (Winick \& Wexler, 2003). Common to all problem-solving courts is the belief that the court needs to address the underlying psychosocial problems that contribute to offending or child abuse and neglect in order to reduce risk of recurrence of problems and return to court. The expectation is that the offender or the substance-misusing parent will, with treatment support, become empowered and learn to take on responsibility for their actions as a pre-requisite to change. In criminal law the process is based on a mixture of incentives and sanctions. In Australia and England, permanent loss of the child at the end of the court process is considered both sufficient incentive and punishment. The principles of problem-solving courts have been articulated (Brook, Akin, Lloyd, Johnson-Motoyama \& Yan, 2016; Choi, 2012) that result in special attention to the process as well as the goals.

The FDTCs draw on the following principles and practices:- 
(1) enhanced court oversight of both participants and services/agencies, with frequent court status hearings beginning a few days after the case is filed and judicial continuity;

(2) intensive case management, including comprehensive assessments of family needs and the developmental situation of the child, and treatment plans to address the findings;

(3) parents are given the option of the FDTC: it is not compulsory;

(4) much greater effort to establish working linkages and coordination among treatment providers, other service providers, and the court;

(5) earlier and more frequent case reviews and development/implementation of service delivery plans that are continually refined to address changing needs identified; and

(6) increased mechanisms to assure accountability of service providers and litigants.

\section{The evolution of family drug treatment courts (FDTCs)}

In tracing the evolution of FDTCs it is important to restate their overall purpose and to highlight how distinctively they seek to tackle the traditional tensions in child protection policy and practice when substance misuse is the major issue. As already stated, FDTCs aim to treat at well as to adjudicate - a radical proposition in the context of parents with problems of substance misuse who do not readily invoke public or political sympathy. Equally radical is the repurposing of the adversarial court process to one that is collaborative and supportive. In contrast to traditional proceedings where the child's needs can be readily seen as in opposition to those of parents, the FDTC seeks to simultaneously consider a plan for the child and a treatment plan for parents, with the ultimate goal of reunifying the family and/or preventing removal of the child if at all possible. If it is ultimately determined that 
reunification is not feasible within a reasonable timeframe, then the FDTC seeks to develop a "permanency" plan that is in the best interest of the child and involves the parent and/or other family members if, and as feasible. The treatment element of the FDTC is a vital component and ensures better access to multi-disciplinary support, but it is time-limited. Hence the FDTC demonstrates that offering treatment to parents under the auspices of the court need not jeopardise the child's needs for a permanent home, whether through reunification or removal, in order to maximise their prospects for a settled future. But the treatment is intensive to give a realistic prospect of addressing the challenges of parental recovery, using motivational approaches led by the judge, and providing regular review so as to foster a therapeutic relationship. In short, the aim of the FDTC is for the court to become an agent of change instead of a last resort that offers a fairer process. The cement that binds together the FDTC courts is their underpinning in therapeutic jurisprudence (TJ), a body of theory and practices that asserts the 'right to a second chance' for reasons of fairness, social justice and the 'recognition of the personal dignity of all persons'(Honneth, 2001). In this way the stigma associated with parents who misuse drugs and alcohol is removed and the commonly reported problem of powerlessness is addressed as part of the treatment package (Harwin, Ryan \& Kershaw, in press).

This ambitious programme developed in all three countries as a response to broad concerns about the contribution of parental substance misuse to child abuse and neglect and the failure of the existing systems to effectively tackle the child abuse and neglect resulting from parental substance misuse problems. Specific shared concerns centred on fragmentation in service delivery whereby adult substance misuse and children's services rarely communicated with each other while a lack of expertise on substance misuse amongst child protection personnel increased the likelihood of court intervention and child removal (Harwin \& Ryan, 2008; Levine, 2012). In England a concern with recurrence - that the same parents appear 
time and time again before the courts - has also prompted and continued to drive the search for innovation (Broadhurst, Alrouh, Yeend, Harwin, Shaw, Pilling \& Kershaw, 2015; Broadhurst, Mason, Bedston, Alrouh, Morriss, McQuarrie, Palmer, Shaw, Harwin \& Kershaw, 2017). The evidence on the harm that parental substance misuse can cause during childhood and adult life (Chaffin, Kelleher \& Hollenberg, 1996; Cleaver, Unell \& Aldgate, 2010; Dawe, Harnett \& Frye, 2008; Felitti \& Anda, 2010; Forrester \& Harwin, 2011; Velleman \& Templeton, 2016) more than compensated for the lack of reliable statistical data on the prevalence of parental substance misuse in care proceedings in England, in "dependency cases" in the USA and care and protection cases in Australia.

Looking at the evolution of FDTCs in each country, what catalysed their development in the USA, was the passage of the Adoption and Safe Families Act (ASFA) in $1997^{3}$. This legislation required the development of a permanency plan for every child removed from their home as a result of parental abuse and neglect within fifteen months of removal. It was intended to put an end to "foster care drift" and promote permanent placement of children who had been removed from their home. ASFA hit a sensitive chord among judges handling child abuse and neglect matters who saw each day the terrible toll which the then current child welfare process wreaked on both children and parents. Armed with the mandate the ASFA now imposed, a cadre of judges from various parts of the country dealing with abuse and neglect cases saw an opportunity to apply the concepts of "immediacy" and "ongoing court supervision" endemic in the successful adult drug court model to the child welfare/abuse and neglect process. Although no national model for family drug courts had been developed, a number of judges developed their own special strategies for meeting both the spirit and requirements of ASFA, in the family drug courts. The principles and practices

\footnotetext{
${ }^{3}$ https://www.gpo.gov/fdsys/pkg/PLAW-105pub189/pdf/PLAW-105pub189.pdf
} 
outlined above became the prototype FDTC model that was exported to England and Australia.

National funding spearheaded the development of FDTCs in the early years of their development providing judicial and child protection training and grants to local courts. Following the enactment of the ASFA, the USA's Department of Justice made available comprehensive training and technical assistance to jurisdictions interested in developing FDTCs, and a limited amount of grant funding that was competitively awarded to local jurisdictions.

As in the USA, the Family Drug and Alcohol Court in England, known as "FDAC", started as a grassroots judicial initiative arising from a chance meeting between an American and English judge. This meeting of pioneers was timely and FDAC's subsequent development as a government pilot in 2008 was greatly aided by its resonance with major concerns and policy initiatives of the Labour administration of the day. The highly influential Hidden Harm Report (Advisory Council on Drug Misuse, 2003) had broken through the silence on parental substance misuse, exposing major gaps in service delivery in all sectors. Drawing on the research of Harwin and Forrester published subsequently in 2007, the report revealed the significant role that parental substance misuse plays in child protection and court-mandated child removal due to the significant harm resulting. Hidden Harm created a climate of public and professional concern and led to a demand for a national strategy to address parental substance misuse.

At the same time, the FDAC proposal fitted well with other major national policy debates. There was major concern about the educational and wellbeing outcomes of children in public care. In the context of a Labour administration committed to family support and prevention, the government established a family drug policy for the first time in 2008 (Home Office, 
2008). When combined with the US national evidence of the success of family drug courts in increasing rates of family reunification through reduced substance misuse and saving costs of foster care (Worcel, Green, Furrer, Burrus \& Finigan, 2007), the argument to set up an FDAC had been won. The pilot court first opened its doors in 2008 in London, co-funded by three government departments until 2012 by the then Department for Children, Schools and the Family, the Ministry of Justice and the Home Office and written into a government White Paper (Harwin \& Ryan, 2008).

The government has continued to play a major role in the evolution of FDACs in England. In a major investigation of family justice which we discuss later, The Family Justice Interim Report of 2011 (Ministry of Justice, 2011a) described FDAC as 'promising' but called for longer term evaluation and evidence of cost effectiveness. The 2017 Government Drug Strategy (HM Government, 2017) noted that Public Health England will work with FDACs and local public health teams, a new direction in terms of building bridges between FDAC and public health (HM Government, 2017). The importance of the government involvement is also reflected in funding arrangements. Nearly all the local FDACs have been part-funded by government mainly, but not exclusively, as a result of its major Social Care Innovation Programme to promote promising initiatives with sustainable prospects. As part of that initiative, 13 new FDAC teams were established in 16 courts, serving 21 local authorities in 2015-2016, supported by the creation of an entirely new body, the FDAC National Unit.

It is too early to talk of the evolution of the FDTCs in Australia, as the first pilot court was only established in 2014 offering a 12 month programme within the Family Division of the Children's Court of Victoria. As in England and the USA, it has been a grassroots judicial initiative led by a magistrate following a Churchill scholarship granted to view FDTCs in the USA and England. The Victoria Court was initially funded in one site for three years from an "innovative court fund" tasked with introducing change to address the increasing number of 
children in the care system. Timing and the obtaining of bi-partisan political support was crucial to its establishment. Despite considerable interest and support by individual children's magistrates in other Australian states and territories, government funding to establish FDTCs beyond the one site in Victoria has, to date, been elusive.

When reflecting on the evolution of FDTCs we can see remarkable parallels between the USA, England and Australia in the catalysts to reform. Judges who recognized the dysfunction of the present "system" for handling child abuse and neglect cases and, at the same time, saw the promise of the drug court approach, were able to drive ahead the agenda successfully in all three countries by fostering local initiatives. In the USA and England the movement took off by skilfully building on wider legislative or policy reform. The role of central government has been particularly important in England since the first FDAC was set up whereas in Australia and the USA these have been primarily local initiatives, although federal funding often planted the seeds to develop pilot programmes and is still available to provide limited technical assistance, training and grant funding in the USA. However, in Australia, the broader adoption of FDTCs has not been supported by national funding or policy, with only the one court established to date dependent on state funding and circumstances at the time.

It is against this background that we now consider why the FDTC movement has stalled and examine a series of inter-connected reasons that help explain the situation.

\section{FDTCs: the operational challenges}

The operational challenges of setting up a FDTC are considerable. A FDTC entails bringing together the justice system and the child protection system- two very separate agencies that have traditionally worked in an adversarial posture in the USA, England and Australia. As already noted, they can also operate in silos, so developing a shared mission, approach and 
mechanisms to promote ongoing communication and information exchange has required significant organisational and cultural changes. In the USA, extensive training and retraining has been essential to help child welfare staff to work effectively in the family court paradigm. However, as a result of internal organisational changes within the USA's Department of Justice regarding the FDTC programme, training, technical assistance and grant funding stopped in 2002 for several years. When additional funding was reinstated a few years later, the training and technical support was more restricted with the result that the cohesive mission and framework of the early FDTCs was not necessarily present.

In England the FDAC National Unit has played an important role in training and upskilling staff but nevertheless a number of operational issues continue to be challenging and limit FDAC's impact on family justice. In the early days some professionals voiced concerns over the extent to which parents' needs were taking precedence over the child's need for permanency. While this concern has receded amongst practitioners working with the FDACs, not all family judges operating ordinary courts believe that the court should have a treatment role. On a more practical front, commissioners of FDAC had hoped that it would be possible to identify the type of case that would most benefit from FDAC so that the service could be targeted to maximise efficiency. However, as in the USA, it has not been possible to provide this evidence. A continuing obstacle to wider roll-out is the need for additional resources to set up the specialist team and for a new FDAC to run for at least three years before new sites can get a true sense of outcomes being achieved. Finally, the original intention of FDAC had been to bring cases to court as early as possible, but one of the main consequences of the Family Justice Review has been to reinforce the idea of the court as a place of last resort and speedy adjudication (Harwin, et al., in press).

In Australia, the ability of the FDTC magistrate and staff to obtain entry for their clientele into drug treatment programmes, and support participants' interactions with services such as 
housing and income support agencies, when these services are experiencing funding challenges and increased demand, has been a challenge and required good working relationships. Senior level support by child protection is crucial for these working relationships.

All these issues have had a number of consequences in both the USA and England. Because the FDTCs depend on the initiative of local judges to provide the leadership and coordination to promote earlier intervention, continuous supervision and necessary support services, when they retire or take on a different role, the courts have been vulnerable to closure unless they can find a successor judge to take on these functions. There is no automatic replacement of the FDTC judge in the USA or England, and it is widely acknowledged that not every judge is suited or has the inclination to run a FDAC. No reliable data are collected in the USA to provide information on the number of FDTCs that are currently operating, let alone the practices and services that they provide. The latest information, based on self-report, suggests there has been a drop from 322 FDTCs in 2009 to 305 in 2014 (Marlowe, Hardin \& Fox, 2016). In England, as already noted, a small number of FDAC teams have closed as new FDACs have been set up. Going forward, government is no longer planning to directly cofund FDACs. Instead, and in line with marketization approaches, FDAC has won on the basis of a competitive tender a new Life Chances Grant of $£ 6.2$ million to support its work over the next 7 years. The scheme is run as a Social Impact Bond so that money is only transferred when projects meet agreed targets. It is a challenging and relatively untested approach.

\section{Tensions in balancing the child's needs for permanence and parental}

\section{timescales for recovery}

Balancing the parents' need for help with their substance misuse and the child's needs for permanency is arguably the most ambitious aspect of the FDTC programme because of the 
profound consequences resulting from the decision whether or not to reunify. It has also been highlighted that working effectively with substance-using parents is one of the major challenges facing child welfare systems (Forrester \& Harwin, 2011; Green, Furrer, Worcel, Burrus \& Finnegan, 2007; Taplin \& Mattick, 2011). This is due to a number of reasons: (i) the high proportion of significant co-occurring problems in this population, and (ii) because child protection and drug treatment service providers generally have differing goals, professional backgrounds and organisational cultures ( Boles, Young, Moore \& DiPirroBeard, 2007; Karoll \& Poertner, 2002), and work with different timeframes and clientele leading to silo-ing and a lack of coordination of services and planning (Grella, Hser \& Huang, 2006; Taplin \& Mattick, 2011).

Sceptics argue that recovery from substance misuse is such a variable and uncertain process that it is unfair to return children home (Barnard, 2006), merely postponing placement with adoptive families or in kinship/foster care. Many say that a minimum of a year in treatment is required, while the international evidence suggests that recovery can take at least three years (Best, Albertson, Irving, Lightowlers, Mama-Rudd \& Chaggar, 2015; Dennis, Scott, Funk \& Foss, 2005). Moreover, the international literature on reunification highlights the special fragility of recovery when parental substance misuse is involved (Farmer, Sturgess, O'Neill \& Wijedasa, 2011).

However, given the high prevalence of, and different levels of substance use, the focus must be on the impacts of the substance use on the child and the ability of the parents to safely care for their children. This is one of the main reasons why FDTCs invest in treatment. In theory it would be possible to eliminate risk by removing all children from parents whose substance misuse is severe enough to trigger care and dependency proceedings, but in reality it is not possible because of shortages of alternative placements. Furthermore, not only does this line of reasoning run counter to the principles of FDTCs, but there is some evidence that 
challenges the inevitability of harm. Research with mothers in treatment for opioid use has found that many have had no involvement with the child protection system (Taplin \& Mattick, 2013). Furthermore, recent research from the National Study of Child and Adolescent Well-Being (NSCAW II) has found no significant differences in well-being levels between children with parents in the home using substances and those without. The authors concluded that children with substance-using parents may be able to remain at home over an extended period after investigation, while maintaining well-being levels similar to children at home with parents not using substances (Orsi, Brown, Knight \& Shillington, 2018).

As regards FDTCs, all three legislative contexts initially provided a largely supportive framework in which to provide a meaningful opportunity to test parental capacity to change whilst ensuring the child remains safe and a parallel plan is developed for out of home permanency- in theory at least. But as Wexler (Wexler, 2014) reminds us, a change in legislation can potentially undermine this delicate balance. The USA, the UK and Australia, one by one have all set tighter timescales for permanency decision-making, with far greater priority being placed on timely placement with forever families, particularly for very young children. The starkest illustration of this tension is seen in the English context where new legislation, the Children and Families Act 2014, introduced a statutory requirement to complete the case within 26 weeks in all but exceptional circumstances. FDAC has indeed been singled out as one of the reasons why a case might be granted permission to continue for longer but approval is not automatic. Moreover, as judges are now monitored on the proportion of their cases that complete within 26 weeks extending timescales can create a tension for every judge.

The persistence of delay in case resolution for children was the driver to the 26 weeks measure in England and was widely welcomed. However, it inevitably reduces the opportunity for a meaningful 'trial for change' in order to attempt reunification. Indeed it has 
more than halved the time available for the FDAC intervention as the duration of proceedings used to frequently take a year. Although the legislation also strengthened the emphasis on pre-proceedings work to compensate for the shorter duration of the court process, a main rationale for FDAC and FDTCs is that the work takes place under the scrutiny of the court and that the part played by the judge is particularly important. In this way we can see the Children and Families Act 2014 weakening the original conception for FDAC as enabling the judge to hear cases earlier and to support them longer within the court setting. If as the literature suggests, the role of the judge is so essential (Edwards \& Ray, 2005; Rossman, Roman, Zweig, Rempel \& Lindquist. 2011), post order supervision of the case by the local authority for a year is an insufficient provision.

\section{Fiscal constraint and neoliberal values: in search of sustainable funding for}

\section{the FDTC}

In considering the progress of the FDTCs internationally, it is important to locate developments in their broader socio-economic context. Prevailing political climates influence funding decisions, which are self-evidently integral to the shaping of justice landscapes. The USA and England, now with a significant history in respect of FDTC development, enable analysis of both central and local funding commitments over time, and the influence of changing political and economic winds. The global fiscal crisis, which emerged in 2008, is an important milestone in this respect, given that it sparked major cutbacks in public funding in a number of international contexts. Causes of the successes and failures of the FDTC, as we outline in this paper, are multiple, but the scale and longevity of funding is a vital consideration given, as we have seen, the organisational challenges in effecting major change in the family courts. In this section we argue, that neither the federalism of the USA nor the centralised approach to policy and legislative development in England have delivered 
sustainable funding for the FDTC treatment approach, with both international jurisdictions feeling the impact of major fiscal constraint as well as further shifts towards neoliberal governance.

In the USA and England concerns with underfunding of justice have a long history, coupled with substantial critique of both the commitment and responsibility of governments to providing the conditions in which justice can be upheld. However, such concerns have arguably become more acute regarding family justice during the past decade, given the combination of rising demand on the courts, coupled with global economic downturn. The fiscal crisis of 2008 has led to widespread retrenchment in public services and justice systems have been far from immune to this fiscal crisis. As Maclean, Eekelaar \& Bastard, $(2015, \mathrm{p} 1$. have described, fiscal constraints has led to "unparalleled turbulence" in family justice systems, largely resulting from drastic reductions in public funding.

Not only have cuts in funding resulted from efforts on the part of nation-states to deal with the fiscal crisis, but, in addition, critics have argued that increasing rationalisation of available public funding has led to an intensification of neoliberal values. Here we refer to political emphasis on individual responsibility, a reduced role for public services, including the family courts, deregulation and privatisation. In this context, it is hard to make the case for the investment of public money in high quality, highly skilled provision for families seen to be making unhelpful 'lifestyle choices' that bear heavily on the public purse.

Turning first to the USA, there is considerable variation in the organisation of the family courts, with States having considerable autonomy in this respect, compared to European counterparts (Wardle \& Nolan, 2011). Although federal law (e.g. ASFA) has considerable influence at the State level, States equally have room for self-organisation. For example, the federal court process has no jurisdiction over child abuse and neglect cases. Therefore, 
whether the FDTC approach has been implemented or currently operates is a local decision, usually closely tied to the interest and initiative of a local judge to develop such a programme. In this context, State level commissioners have been the primary focus of pioneers, advocating for the FDTC model. Aside from central funding committed in 2002, by the USA's Department of Justice regarding the FDTC programme, the sustainability of any court innovation is heavily dependent on State-level funding. The strength of federalism in relation to the development of law and practice is that local States can more readily innovate and serve as laboratories for the testing of home grown and home tailored solutions (Wardle \& Nolan, 2011). In addition, developments in one State can certainly influence others particularly in relation to promising interventions. However, States operating under federalism are not immune to cuts to their budgets, indeed the financial health of States remains highly sensitive to national financial health in the USA, creating or restricting the conditions for social investment and innovation.

Preceding the fiscal crisis, the USA had already pursued regressive tax cuts, which coupled with a decline in economic growth, served to restrict government revenue. Under the George W Bush administration (from 2001), a further shift to the right was clearly discernible with continued cuts to taxation and associated cuts to public spending (Crotty, 2012). In 2008 the global economic crisis, which had its roots in the USA led to further retrenchment in social investment. Analysis of retrenchment at the State level indicate that States generally followed central government in cutting public services to deal with budget deficits, including social investment (Lobao \& Adua, 2011). This fiscal situation, coupled with a traditional "silo" and localized, ad hoc approach for dealing with parental substance misuse, let alone its effects on children, have been major factors in slowing down the momentum for FDTC development.

In contrast to the USA, England has a highly centralised rather than devolved family justice system and major innovation requires central government support. Local authorities have 
some flexibility in the management of budgets, but because they are tied to national mandates regarding the operation of services and are regularly inspected against national indicators of performance by Ofsted, this greatly limits innovation. In addition, family judges are accountable to the leading national family judge - the President of the Family Division which again indicates considerable central influence.

Regarding the first FDAC pilot in England, support for this was found in the Labour government of the time and from the then President of the Family Division (Sir Nicholas Wall). However, shortly after FDAC was established in 2008, a new Coalition Government elected in 2010, called for wholesale review of the Family Justice System to tackle costs and inefficiencies. This wholesale reform was catalysed by broader concerns about public spending and political desire to reduce the role of the state in family life. The fiscal crisis of 2008 required government action, but equally paved the way for a right-of-centre administration to more readily make the case of major cut backs in public spending. The final report of the Family Justice Review (Ministry of Justice 2011b) was to recommend unprecedented cuts to legal aid in private family matters and in public law, radically shorter timescales and a reduction on the role of experts, as described above for care proceedings. These changes in both public and private law, although differently configured, can both be seen as having cost-savings at the heart of revision. Despite fierce opposition from leading professional associations (Association of Lawyers for Children) and powerful critical analysis from leading academics about a perceived demise of family justice (Eekelaar, 2011), the counter-narrative was insufficient to stall major reform. Indeed, fiscal constraint and assault on perceived 'bloated' public services under the Coalition Government (2010-2015), also led to a major reduction in the capacity and expertise within central government ministries. This direction of travel has not abated, indeed, the subsequent election of David Cameron's Conservative government in 2015, and current challenges of Brexit has done little to ease 
austerity. In this context, despite the promise of FDAC and a sense of crisis as care demand threatens to overwhelm the family courts, energy and resources for innovation within local authorities are in short supply.

Leading critics (Dean, 2014) have argued that family law, in the context of neoliberalism, is focused largely on the protection of negative liberties (e.g. freedom from ill-treatment), but with a much-reduced role in support of positive rights or the resources that enable families to prosper in the face of adversity (e.g. rights to treatment or rehabilitation). Changes brought with the wholesale review of justice, certainly created a more challenging political and economic context for England's FDAC which in contrast championed better justice and expanded role for the courts. In England, Australia and the USA, the sentiments of therapeutic jurisprudence arguably run counter to the key tenets of neoliberalism. These are neoliberalism's emphasis on individual responsibility, a minimal role for the state and welfare retrenchment. As we have seen in England, families are increasingly expected to look after their own needs without resorting to making demands on the 'public' purse. In this context, the Family Drug Treatment Courts are seen as resource intensive and potentially 'wasted' on parents unable to sustain change. Finding alternative adoptive placements for very young children is a more palatable alternative than offering longer-term support to parents where outcomes are uncertain. So too is placement within the extended family under special guardianship, which as a private law provision, frees the local authority from the continuing responsibility and the cost of looking after children. Certainly in England, support for parents is far more grudging given successive governments' emphasis on public spending constraint and family self-sufficiency (Pantazis, 2016). Government needs to find permanent alternative carers for young children in particular, but a mandate to mitigate the poverty, distress, isolation or trauma experienced by parents, has weakened under successive rightwing governments. 
Proponents of the FDTCs have endeavoured to speak to political concerns regarding fiscal constraint, thorough heralding the cost-savings that can result from an alternative approach to family proceedings. However, arguments have not been sufficient to persuade national or federal governments to embrace the major reform that the FDTC proposes. In this context, resource issues have dogged the development of the FDTCs. In England, piecemeal funding from different government ministries, seeming to battle amongst themselves in regard to financing FDAC, has not inspired local authorities with confidence. In austere times, investing both time, money and energy in alternative treatment courts with no promise of ongoing financial support from government has been unattractive.

It is rather early to consider how FDTCs will fare in Australia. However, it is possible to conclude that in Australia too, a largely devolved approach to policy, legislative and practice development in many respects enables a local laboratory culture, as in the USA. However, as we have seen from the above discussion, neither federalism nor centralised investment appears to have, as yet, secured the conditions for financial sustainability of the FDTCs in England, the USA or in Australia.

\section{The contribution of evaluation - a missed opportunity?}

The role of evaluation is crucial in testing the impact of any innovation. Indeed, an unusual feature of introducing FDAC in England was the government's requirement to carry out an independent evaluation. However, robust evaluations of FDTCs are not easy. FDTCs are a complex and multi-stranded intervention whose impact is felt on children and parents' lives, as well as on courts, children's services, health and criminal justice agencies. Capturing these impacts across the board is a major challenge. Moreover, unlike health settings where randomised controlled trials are seen as essential to assess the impacts of new interventions, there is no such tradition in American or English courts. An abiding concern of the judiciary 
in USA is whether a control group without access to the intervention could litigate on the basis of being denied "equal protection of the laws"4 or other human rights protection grounds, particularly if there is some evidence of the intervention achieving better outcomes. As a result, evaluations have relied on quasi-experimental approaches, widely considered less rigorous, and use of administrative data which is not collected for research purposes. Longitudinal follow up is notoriously challenging in terms of case attrition and costs. For the USA, England and Australia, a further major challenge has been the slow pace at which a sufficient number of cases enter the programme to enable meaningful statistical evaluation of outcomes. No evaluation of the Australian FDTC pilot has as yet been published.

Despite these challenges, the limited quantitative evidence on the outcomes of FDTCs compared to business-as-usual has been positive. As already noted, the US national evaluation of the FDTCs showed better reunification rates, largely attributed to success in addressing parental substance misuse, and with it lower costs of foster care (Worcel et al., 2007; Green et al., 2007). The difference in outcomes was statistically significant. These results have resonated with the evaluation of the English London FDAC at the end of the proceedings, which showed similar improved outcomes (Harwin et al., 2014).

The limited available evidence on parental and professional testimony is also largely positive. All but 2 of 37 London parents who had received the FDAC intervention supported the continuation of the London FDAC and those with experience with the ordinary court process highlighted the differences (Harwin et al., 2014). Parents felt they had previously been treated as 'junkies' or 'prostitutes'. Instead of trying to help us', commented one parent about children's services, 'it felt as if they were trying to find the case to put against us'. The focus groups with professionals also endorsed FDAC: in the words of one lawyer, 'the whole

\footnotetext{
${ }^{4}$ See U.S. Constitution, Fourteenth Amendment. http://www.14thamendment.us/amendment/14th_amendment.html
} 
FDAC philosophy is that the approach CAN work - and parents get that message very early on, whereas in other cases parents feel everyone has given up on them'.

Finally, the limited cost evaluation studies from England and the USA have been largely positive, citing potential savings resulting from reduced out-of-home placements (Marlow et al.2016; Reeder \& Whitehead, 2016). These savings relate not only to children's social care and the courts, but could potentially produce savings for the health and criminal justice system.

The evaluations nevertheless have not proved sufficiently persuasive to secure the longer term futures of FDTCs. There are many reasons for this. With regard to scientific rigour, there has been a lack of information on how cases are selected for the programme. In England the decision is made prior to initiating proceedings by the local authority at a legal planning team meeting, but the follow-up of cases in the evaluations only begins once the case is in court. There is also a lack of information in both the USA and England on the outcomes for the many parents who either did not participate or were terminated from the FDTC. Participants in FDTCs represent a very limited proportion of dependency cases in the USA and England. In the USA there is a similar absence of information on eligibility criteria and the consistency with which these criteria are applied, what happens in cases where reunification is not feasible, as well as the demographic characteristics of the parents and children served.

Moreover, there has been a lack of long-term follow-up of case outcomes in the USA, and none at national level which would allow for individual court findings to be combined and the results are inconclusive (Harwin, Broadhurst, Alrouh, McQuarrie \& Golding, forthcoming). A recently completed evaluation of the longer-term outcomes of the London FDAC found some encouraging results regarding the sustainability of parental substance 
misuse cessation and safe reunification, but in relation to the latter, results were constrained by the small sample, itself determined by court decisions on who to reunify. Moreover, evaluations often cannot capture and keep pace with changes in law, policy, and available resources: the English evidence all relates to the pre-2014 legislation.

The evaluation evidence on FDTCs can also be criticised for insufficiently connecting with the wider debates about the best ways of enhancing the futures of neglected and abused children affected by parental substance misuse. There has been no cross-national debate amongst FDTC professionals about the advantages and drawbacks of the disease and social models that underpin concepts of recovery. Summarising conceptual debates is beyond the scope of this paper and reflect within and inter-country differences regarding harm minimisation and abstinence/child protection models (Lancaster, Duke \& Ritter, 2015). However it is important to note that the different conceptual approaches can influence FDTC goals, their definitions of success and how outcomes are measured and either reinforce or challenge the view that the abstinence model is the only suitable approach when safe parenting is the issue.

The studies have been somewhat insular in their focus, prioritising questions about reunification and its outcomes and cessation of misuse without attention to measuring changes in mental health, domestic violence, and still less on entry into employment or retraining, and deprivation and poverty issues. These gaps in evidence fly in the face of the literature which shows that attention to all these recovery domains is crucial in order to build assets capital (ACMD, 2015). The Engaging Moms randomised control study is one of the few to include a wider set of psychosocial outcome measures (Dakof, Cohen, Henderson, Boustani, Blackburn, Venzer \& Hawes, (2010). However the consistent lack of robust information on FDTC outcomes around housing and deprivation restricts their capacity to contribute to policy debates on the wider context to parental substance misuse and their 
implications for service reform, when the importance of these factors is well documented (Canfield, Radcliffe, Marlow, Boreham \& Gilchrist, 2017).

Moreover, most studies have not considered what happens to children placed in different forms of alternative care and similarly what happens to their mothers, the majority of FDTC clientele. These mothers become invisible in English administrative data unless a new child is born or new evidence of significant harm emerges in relation to other children of the birth mother living at home. This situation is similar for the USA. For the USA, there are few if any process evaluations that might provide a framework for reporting the actual services being provided, the operational procedures in place, timelines for service delivery, participant monitoring, milestones being achieved, and, most importantly, the degree to which "fidelity to the model" and adherence to key FDTC programmatic elements are being achieved.

Finally, as already noted, with regard to costs, the evaluations generally focus on cost-savings from reduced days in out-of-home placements but there are many other costs that need investigation.

These gaps in evidence are particularly troublesome at a time of fiscal austerity and in a neoliberal political environment. Without being addressed, it is easy to marginalise FDTCs.

\section{Discussion and conclusions}

When we compare the evolution of the FDTCs, we see clear commonalities between the USA, England and Australia. In all three countries, FDTCs have started as local or regional innovations, rather than having their genesis in federal or national policy innovation. Pioneering advocates of family court change have been highly influential in steering the development of these courts but there is no structure in place to sustain their development once these pioneering advocates retire, are reassigned, or otherwise step down. 
The USA and England have sufficient history in regard to the FDTCs to enable comparison of obstacles encountered in each of these countries that have limited their progress, and again we see marked commonalities. Neither in the USA or England, has the development of the FDTC led to major policy reform or wholesale adoption of a problem-solving approach for dealing with child abuse and neglect cases involving parental substance misuse. Evaluative evidence, whilst consistent internationally in terms of better outcomes regarding substance misuse cessation of parents participating in these programmes, has been insufficient to persuade governments of the need for wholesale family court reform. In part this may be the result of the very limited number of parents participating in FDTCs compared with the totality of these cases that courts are dealing with daily. It may also be linked to the failure of FDTC evaluation studies to provide comprehensive operational and outcome data on the universe of cases and litigants FDTCs should target compared with those who are actually served. There is also need for more information on the range of services the FDTCs are providing and their impacts compared with those provided in the traditional child abuse and neglect case process. These issues - and others - are critical to fully describing the nature and significance of the interventions and accountability the FDTC model is introducing and its tremendous potential for more effective services to families involved in child abuse and neglect matters.

The FDTCs are a radical innovation that have begun to tackle the many challenges endemic in assisting parents whose substance misuse seriously threatens the welfare of their children not the most sympathetic group of clients - whilst ensuring that the needs of their children are not compromised. In this way, they have managed to make a group of parents often seen as the least deserving of all as worthy of assistance for themselves as well as their children. This shift in public and professional perception should not be underestimated. 
Notwithstanding the shortage of the sound data needed to demonstrate the far-reaching value of the FDTC approach, perhaps the most significant contribution which the FDTCs have made to date is the change in paradigm they are introducing in terms of the way the "system" handles child abuse and neglect cases. They are helping bring about a shift from a primarily administrative process orientation to one that focuses on addressing the underlying - and often considered intractable -- problems that bring these cases into the "system" in the first place. The interrelationship between parental substance misuse and child abuse and neglect has reached epidemic proportions in many locales in the USA ${ }^{5}$ and the ramifications entail many domains for both the parent and the child. The situation is not an easy fix but the FDTC model provides an initial framework for bringing together the multi-disciplinary resources, such as mental health, public health, employment, housing, income support, that research has shown to be critical to address substance misuse and restore healthy family relationships and reunification if feasible. The value of moving further forward with the FDTC model would seem to be self-evident, for the sake of both the parents and the children. While documentation and evaluation of FTDCs is critical perhaps equally important is to evaluate and document the current "system" for handling abuse and neglect matters so that the need and potential implications of the FTDCs can be adequately recognized."

But the article has also shown that the likelihood of embedding FDTCs systematically is tilting at windmills. There is no institutional framework and the current wider political and economic environment is at odds with the FDTC initiative. In England a reduced role for the court following the introduction of the 2014 Children and Families Act is likely to keep FDAC at the margins as a specialist initiative. Even if a vigorous evaluation agenda is introduced to take on board some of the current deficits, FDTCs are perhaps best seen as a

\footnotetext{
${ }^{5}$ http://nic.unlv.edu/pcan/files/parental alcohol.pdf?doclD=125, https://www.drugabuse.gov/international/abstracts/relationship-between-parental-childs-substance-abuseother-problems
} 
powerful social movement, driven by committed and idealistic family justice practitioners who will always exist. But, presently, the FDTC offer is likely to remain the exception rather than the norm. 


\section{References}

Advisory Council on the Misuse of Drugs (2003). Hidden Harm-Responding to the needs of children of problem drug users. Retrieved $24^{\text {th }}$ January 2018 from https://www.gov.uk/government/publications/amcd-inquiry-hidden-harm-report-onchildren-of-drug-users

Barnard, M. (2006). Drug addiction and families. London: Jessica Kingsley Publishers.

Best, D., Albertson, K., Irving, J., Lightowlers, C., Mama-Rudd, A., \& Chaggar, A. (2015). The UK Life in Recovery Survey 2015 : the first national UK survey of addiction recovery experiences. Retrieved $24^{\text {th }}$ January 2018 from http://shura.shu.ac.uk/12200/

Boles, S. M., Young, N. K., Moore, T., \& DiPirro-Beard, S. (2007). The Sacramento Dependency Drug Court: Development and Outcomes. Child Maltreatment, 12(2), $161-171$.

Broadhurst, K., Alrouh, B., Yeend, E., Harwin, J., Shaw, M., Pilling, M., \& Kershaw, S. (2015). Connecting Events in Time to Identify a Hidden Population: Birth Mothers and Their Children in Recurrent Care Proceedings in England. The British Journal of Social Work, 45(8), 2241-2260.

Broadhurst, K., \& Mason, C. (2017). Birth Parents and the Collateral Consequences of Courtordered Child Removal: Towards a Comprehensive Framework. International Journal of Law, Policy and the Family, 31 (1), 41-59.

Broadhurst, K., Mason, C., Bedston, S., Alrouh, B., Morriss, L., McQuarrie, T., Palmer, M., Shaw, M., Harwin, J., \& Kershaw, S., (2017) Vulnerable Birth Mothers and Recurrent Care Proceedings. Final Report. Lancaster: Lancaster University. Retrieved $24^{\text {th }}$ January 2018 from http://wp.lancs.ac.uk/recurrentcare/files/2017/10/mrc_final_main_report_v1.0.pdf. 
Brook, J., Akin, B. A., Lloyd, M. H., Johnson-Motoyama, M., \& Yan, Y. (2016). Family Drug Treatment Courts As Comprehensive Service Models: Cost Considerations. Juvenile and Family Court Journal, 67(3), 23-43.

Canfield, M., Radcliffe, P., Marlow, S., Boreham, M. and Gilchrist, G., 2017. Maternal substance use and child protection: a rapid evidence assessment of factors associated with loss of child care. Child abuse \& neglect, 70, pp.11-27.

Chaffin, M., Kelleher, K., \& Hollenberg, J. (1996). 'Onset of physical abuse and neglect: psychiatric, substance abuse, and social risk factors from prospective community data', Child abuse \& neglect, 20(3), 191-203.

Choi, S. (2012). Family Drug Courts in Child Welfare. Child and Adolescent Social Work Journal, 29(6), 447-461.

Cleaver, H., Unell, I., \& Aldgate, J. (2010). Children's Needs-Parenting Capacity: Child abuse: Parental mental illness, learning disability, substance misuse, and domestic violence. 2nd edn. London: The Stationery Office.

Cooper, C. (2017). Drug Treatment Courts and Their Progeny in the U.S.: Overcoming Their Winding Trajectory to Make the Concept Work for the Long Term. International Journal for Court Administration, 8(3).

Crotty, J. (2012). The great austerity war: what caused the US deficit crisis and who should pay to fix it? Cambridge Journal of Economics. 36 (1), 79-104.

Dakof, G.A., Cohen, J.B., Henderson, C.E., Duarte, E., Boustani, M., Blackburn, A., Venzer, E. and Hawes, S., 2010. A randomized pilot study of the Engaging Moms Program for family drug court. Journal of substance abuse treatment, 38(3), pp.263-274.

Dawe, S., Harnett, P., \& Frye, S. (2008). Improving outcomes for children living in families with parental substance misuse: What do we know and what should we do. Child 
Abuse Prevention Issues. Retrieved $24^{\text {th }}$ January 2018 from

http://www.aifs.gov.au/nch/pubs/issues/issues29/issues29.html.

Dean, H. (2014) Welfare rights and social policy, London: Routledge

Dennis, M. L., Scott, C. K., Funk, R., \& Foss, M. A. (2005). The duration and correlates of addiction and treatment careers. Journal of Substance Abuse Treatment, 28(2, Supplement), S51-S62.

Edwards, J.L.P. and Ray, J.J.A., 2005. Judicial perspectives on family drug treatment courts. Juvenile and Family Court Journal, 56(3), pp.1-27.

Eekelaar, J. (2011). "Not of the Highest Importance": Family justice under threat. Journal of Social Welfare and Family Law, 33(4), 311-317.

Farmer, E., Sturgess, W., O’Neill, T., \& Wijedasa, D. (2011). Achieving successful returns from care: What makes reunification work? London. BAAF.

Felitti, V. J., \& Anda, R. F. (2010). The relationship of adverse childhood experiences to adult health, well-being, social function, and healthcare. In R Lanius, E Vermetten \& C Pain. The Impact of Early Life Trauma on Health and Disease the Hidden Epidemic. Cambridge: Cambridge University Press

Forrester, D. and Harwin, J., 2007. Parental substance misuse and child welfare: outcomes for children two years after referral. British Journal of Social Work, 38(8), pp.1518-1535.

Forrester, D., \& Harwin, J. (2011). Parents Who Misuse Drugs and Alcohol: Effective Interventions in Social Work and Child Protection. Chichester: Wiley-Blackwell.

Green, B. L., Furrer, C., Worcel, S., Burrus, S., \& Finigan, M.W. (2007). How Effective Are Family Treatment Drug Courts? Outcomes From a Four-Site National Study. Child Maltreatment, 12(1), 43-59. 
Grella, C. E., Hser, Y. I., \& Huang, Y. C. (2006). Mothers in substance abuse treatment: Differences in characteristics based on involvement with child welfare services. Child Abuse \& Neglect, 30, 55-73.

Harwin, J., \& Ryan, M. (2008). The Role of the Court in Cases Concerning Parental Substance Misuse and Children at Risk of Harm. Journal of Social Welfare and Family Law, 29 (3-4), 277-292.

Harwin, J., Alrouh, B., Ryan, M., \& Tunnard J. (2014). Changing Lifestyles, keeping children safe: an evaluation of the first Family Drug and Alcohol Court (FDAC) in care proceedings. London: Brunel University. Retrieved $24^{\text {th }}$ January 2018 from http://wp.lancs.ac.uk/cfj-fdac/publications/.

Harwin, J., Alrouh, B., Ryan, M., McQuarrie, T., Golding, L., Broadhurst, K., Tunnard, J., \& Swift, S. (2016). After FDAC: outcomes 5 years later, Final Report. Lancaster: Lancaster University. Retrieved $24^{\text {th }}$ January 2018 from http://wp.lancs.ac.uk/cfjfdac/publications/.

Harwin, J., Broadhurst, K., Alrouh, B., McQuarrie, T., \& Golding, L. (2018) Child and parent outcomes in the London Family Drug and Alcohol Court five years on: building on international evidence. International Journal of Law, Policy and the Family.Doi:10.1093/lawfam/eby006

Harwin, J., Ryan, M., \& Kershaw, S. (in press). The Family Drug and Alcohol Court: a problem-solving approach to family justice. In M. Shaw, \& S. Bailey (Eds), Children: A developmental perspective, Cambridge: Cambridge University Press.

HM Government (2017). 2017 Drug Strategy. Retrieved 24 $4^{\text {th }}$ January 2018 from https://www.gov.uk/government/uploads/system/uploads/attachment_data/file/628148 /Drug_strategy_2017.pdf. 
Home Office (2008). Drugs: protecting families and communities-2008. London. Retrieved $24^{\text {th }}$ January 2018 from

http://webarchive.nationalarchives.gov.uk/20100419085703/http://drugs.homeoffice.g ov.uk/publication-search/drug-strategy/drug-strategy-2008.

Honneth, A. (2001). Recognition or redistribution? Changing perspectives on the moral order of society. Theory, Culture \& Society,, 18 (2-3), 43-55.

Karoll, B.R., \& Poertner, J. (2002). Judges', caseworkers', and substance abuse counselors' indicators of family reunification with substance-affected parents. Child Welfare, 81(2), 249-269.

Lancaster, K., Duke, K. \& Ritter, A., 2015. Producing the 'problem of drugs': A cross national-comparison of 'recovery' discourse in two Australian and British reports. International Journal of Drug Policy, 26(7), pp.617-625.

Levine, G. (2012). A study of Family Drug Treatment Courts in the US and England: Giving parents and children the best chance of reunification. Retrieved $24^{\text {th }}$ January 2018 from https://www.churchilltrust.com.au/media/fellows/2011_Levine_Greg.pdf

Lobao, L.M., \& Adua, L. (2011). State rescaling and local governments' austerity policies across the USA, 2001-2008, Cambridge Journal of Regions, Economy and Society. 4 (3), 419-435.

Maclean, M., Eekelaar, John, \& Bastard, Benoit. (2015). Delivering family justice in the 21st century (Oñati international series in law and society).

Marlowe, D.B., Hardin, C.D., \& Fox, C.L (2016). Painting the Current Picture: A National Report on Drug Courts and Other Problem-Solving Courts in the United States. Washington: National Drug Court Institute. Retrieved $24^{\text {th }}$ January 2018 from http://www.nadcp.org/sites/default/files/2014/Painting\%20the\%20Current\%20Picture \%202016.pdf. 
Ministry of Justice (2011a). Family Justice Review: Interim Report. London. Retrieved 24 ${ }^{\text {th }}$ January 2018 from https://www.gov.uk/government/publications/family-justicereview-interim-report.

Ministry of Justice (2011b). Family Justice Review: Final Report. London. Retrieved $24^{\text {th }}$ January 2018 from https://www.gov.uk/government/publications/family-justicereview-final-report.

Munby, J. (2014). The Process of Reform Next Steps View from the President's Chambers, 12. Family Law, 42, 680-683 \& 816-820.

Orsi, R., Brown, S. M., Knight, K. E., \& Shillington, A. M. (2018). Remaining home: Wellbeing outcomes and co-occurring parental substance use following a maltreatment investigation in middle childhood. Children and Youth Services Review, 84, 118-124.

Pantazis, C, Policies and discourses of poverty in times of recession and austerity, Critical Social Policy, Critical Social Policy 2016, Vol. 36(1): 3-20.

Reeder, N. \& Whitehead, S. (2016). Better Courts: the financial impact of the London Family Drug and Alcohol Court, London: Centre for Justice Innovation. Retrieved $24^{\text {th }}$ January 2018 from http://justiceinnovation.org/wp-content/uploads/2016/09/BetterCourts-The-Financial-Impact-of-the-London-FDAC.pdf

Review Group (2016). Review of Civil and Family Justice: The Review Group's Draft Report on Family Justice, August 4, 2016. Retrieved 24 ${ }^{\text {th }}$ January 2018 from http://niopa.qub.ac.uk.

Rossman, S.B. Roman, J.K. Zweig, J.M., Rempel, M. \& Lindquist, C.H. 2011. The multi-site adult drug court evaluation: The impact of drug courts.

Taplin, S., \& Mattick, R. P. (2011). Family Drug Courts: An Option for the Australian Child Protection System. Developing Practice: The Child, Youth and Family Work Journal (28), 13-22. 
Taplin, S., \& Mattick, R. P. (2013). Mothers in methadone treatment and their involvement with the child protection system: A replication and extension study. Child Abuse \& Neglect, 37(8), 500-510.

Velleman, R., \& Templeton, L.J. (2016). Impact of parents's substance misuse on children: an update. BJ Psych Advances, 22 (2) 108-117.

Wardle, L.D., \& Nolan, L.C. (2011). Family Law in the USA. Kluwer Law International.

Wexler, D. B. (2014). New wine in new bottles: The need to sketch therapeutic jurisprudence code of proposed criminal processes and practices. Arizona Summit Law Review, 7(3), 463-480.

Winick, B. (2002). Therapeutic jurisprudence and problem solving courts. Fordham Urban Law Journal, 30(3), 1055-1090.

Winick, B., \& Wexler, D. (2003). Judging in a therapeutic key: Therapeutic jurisprudence and the courts. Durham, North Carolina: Carolina Academic Press.

Worcel, S.D., Green, B.L., Furrer, C.J., Burrus, S.W., \& Finigan, M.W. (2007). Family Treatment Drug Court Evaluation: Final Report. Portland, OR: NPC Research. Retrieved $24^{\text {th }}$ January 2018 from http://npcresearch.com/wpcontent/uploads/FTDC_Evaluation_Final_Report.pdf.

Worcel, S. D., Furrer, C. J., Green, B. L., Burrus, S. W. M., \& Finigan, M. W. (2007). Effects of family treatment drug courts on substance abuse and child welfare outcomes. Child Abuse Review, 17(6), 427-443. 